\title{
The role of Quality Strategic Planning on Organisational Success
}

\author{
Gideon N. Neluheni \\ Werner Pretorius \\ Wilfred I. Ukpere
}

\author{
Department of Industrial Psychology and People Management, \\ Faculty of Management, University of Johannesburg, Johannesburg, South Africa \\ E-mail: wiukpere@uj.ac.za
}

Doi:10.5901/mjss.2014.v5n1p697

\section{Abstract}

The purpose of this study was to bring to an end the debate that has been fuelled by the fact that many strategies fail whilst others are not implemented at all or at best only partially implemented. Finding a solution to this burning issue is crucial to all organisations in the current turbulent and volatile business environment. The problems that cause strategic plans to fail are categorised by literature into the strategy planning process, a quality strategy, implementation of the strategy as well as the organisation structure and climate. When cause-and-effect is applied to this categorisation, it follows that process drives quality, which in turn drives rate of success or failure in the implementation of the strategic plan. Although it is recognised that there are numerous contextual factors that impact on the successful implementation of a strategic plan, it is postulated that the quality of the strategic plan is core to its success. It therefore follows that a well-conceived and a good quality strategic plan would lead to flawless implementation and a significant superior performance. The purpose of this study is to confirm this assertion. The research methodology adopted was the descriptive quantitative research. A self-administered survey questionnaire was used to collect data in which the respondents are asked to complete by themselves. The research methodology will enable the researcher to observe, analyse and then interpret what has been observed. The findings of the research confirmed the researcher's hypothesis. The confirmation is to the effect that a well-conceived and a good quality strategy lead to flawless implementation, organisational competitiveness and effectiveness.

Keywords: Balanced scorecard, Strategic plan, Strategy implementation, Performance management system, Quality practices.

\section{Introduction}

There is much debate as to the effectiveness and impact of strategic planning on long term organisation success. This debate has led some organisations to abandon their strategies and resort to quick solutions and short-sighted survival tactics to stay afloat. This may be an indication that strategic planning may be undergoing its own identity crisis (McGraw, 2009:1).

In recent times South African newspapers are packed with news of organisations that are either being sequestrated or liquidated because of the failure of their strategic plans. Recently the financial crisis across the globe notably in the United States of America and Europe hit the foundations of several organisations to the ground due to the failure of their strategic plans (Ferguson, 2008:18).

The debate is further fuelled by the fact that so many strategies fail whilst others are not implemented at all, or are at best partially implemented. There are several underlying causes that can lead to the failure of strategic plans (Olsen, 2007:264-265; Resnick, 2010:1; Khadem, 2008:1). Literature shows that the failure of the strategic plans fall into four categories. These categories are the strategy planning process, quality of the strategy, implementation of the strategy as well as the organisation structure and climate (Resnick, 2010:1; Khadem, 2008:1; Köseoğlu, Barca, Karayormuk \& Edas, 2009:84). If cause and effect is applied to this categorisation, it follows that process drives quality, which in turn drives rate of success or failure in the implementation of the strategic plan. Although it is recognised that there are numerous contextual factors that impact on the successful implementation of a strategic plan, it is postulated that the quality of the plan is core to its success.

However, literature is silent on the impact which the quality of strategic planning has on the effectiveness of a performance management system to successfully implement strategies. This study therefore postulates that the lack of quality strategic planning prevents organisations from implementing their strategic plans. Confirmation of this supposition 
will have a significant impact on organisations that wish to embrace the development of quality strategic plans to enhance implementation of their strategies.

The implication of the above means that there is a cause-and-effect relationship between strategy development and strategy implementation. Strategy formulation without strategy implementation is useless (Hrebeniak, 2008:3; Čater \& Pučko, 2010:214). This study will demonstrate that the quality of the independent variable determines the quality of the dependent variable. In that case, a poorly designed and developed strategy will result in poor implementation (Čater \& Pučko, 2010:214). By looking at the quality of the independent variable, one would be able to predict the quality of the dependent variable (Bless \& Higson-Smith, 2004:25 \& 42).

\section{Problem statement}

The problem of strategic planning failure is a world-wide phenomenon and of such a magnitude that $90 \%$ of the strategic plans fail while only $10 \%$ of the strategic plans were being successfully implemented. It is said that $95 \%$ of organisations do not even understand their organisational strategies (Čater \& Pučko, 2010; Speculand, 2009). The failure of strategic plans has left a trail of destruction. The case in point is the 2008 financial crisis in the United States of America and Europe. Billions of dollars were lost; millions of people became unemployed leading to foreclosure of their mortgage bonds. All these left a dented economy (Ferguson, 2008:18-21).Many factors impact the quality of strategic planning and strategy implementation and the quality of strategic planning impacts on overall organisational success. The strategy formulation, strategy implementation relationship is the crux of the cause of failure or success of organisations.

\section{Research Objective}

The objective of this study was to explore the reason why many strategies fail whilst others are not implemented at all or at best only partially implemented. Finding a solution to this burning issue is crucial to all organisations in the current turbulent and volatile business environment.

\section{Literature Review}

Organisations whose foundations are built on quality strategies and practices become world-class organisation (Parker, 2007:12-13; Khan, 2007:1). Such organisations become "the crown jewels in their industries, widely admired by their peers and having a long track record of making a significant impact on the world around them" (Collins \& Porras, 2005, p. 1). Leap-frogging into world-class or visionary organisations does not happen by chance nor is it an overnight exercise. Clear guidelines, processes and world-class practices must first be identified and the route plotted. Then step-by-step, brick-by-brick, the strategic planning process must begin (Parker, 2010).

The strategic planning process framework will be based on three foundational pillars. These pillars are the strategic planning process, a performance management system and lastly, policy development and audit. All three components are interdependent to one another and must seamlessly integrate to ensure organisational success (Parker, 2010, Workshop). Parker (2010) gives an overview of the planning process flag-posts as follows:

- Preparation phase;

- Overview of the strategic planning process;

- $\quad$ The strategic intent;

- $\quad$ Taking 360 degree stock;

- $\quad$ Formulation of the strategy;

- Refining and consolidating the strategic plan;

- Implementing the strategic plan; and

- Evaluating the strategic plan.

\section{Strategic Planning Process}

A strategic planning process is a step-by-step, ongoing and results-oriented roadmap that enables the organisation to achieve its mission and vision (Grensing-Pophal, 2011:4). The roadmap is rolled out for the next two to three years (Shapiro, 2010:4; Grensing-Pophal, 2011:5). The strategic planning process needs to be documented as ongoing activities because like desert sand, the business terrain keeps on changing in an unpredictable manner (Cru Press 
Green, 2010:1; Grensing-Pophal, 2011:5). When the changes are like a hurricane, they can wreak havoc and destroy everything in their paths depending on their velocity (Von Eck, 2007:16).

The strategic planning process therefore involves the strategic planning, implementation, monitoring and evaluation (Schilder, 2010:1). It focuses on the organisation's critical success factors that could enable it to achieve its mission and be able to surmount the turbulent and unpredictable hostile business environment (Cru Press Green, 2010:1). In that way, the strategic planning process creates certainty to the future of the organisation (Grensing-Pophal, 2011:4). The following paragraphs will focus on the phases of the strategic planning process, which is also illustrated in Figure 1 below.

\section{Figure 1: The Strategic Planning Process}

\section{The Strategic Planning Process}

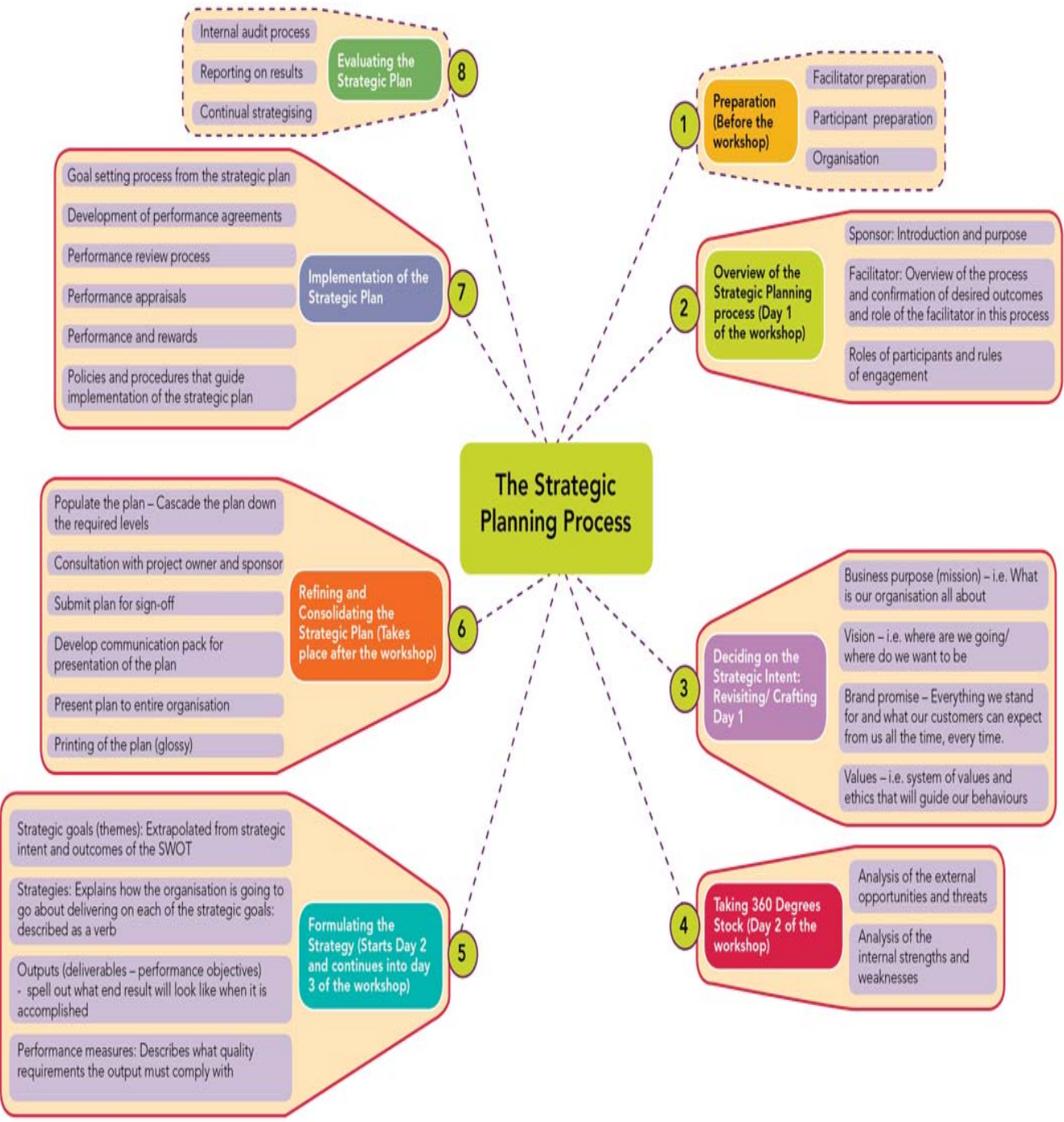

Source: Parker (2010). 


\section{Preparation Phase}

Whoever wants to be involved in the strategic planning process need to know what comes first and what comes last. The route to quality strategic planning or world-class practices begins with the facilitator's preparation, participant preparation and the preparation of the organisation (Parker, 2010). Unless things are done right the first time, it cannot be expected that they would be fixed at a later stage (Frigon \& Jackson, 2009:1).

The strategic planning process can be an emotional exercise where the emotions of the participants can at times run high. It is therefore recommended that an outside facilitator should be required to handle the strategic planning process. He should be skilled in leading the group and have the required expertise related to the strategic planning process. His main role is to move the group to its desired outcome (Grensing-Pophal, 2011:42). In addition to the facilitator preparation, the preparation phase should have participants who would conduct the strategic planning process. Participants to the strategic planning process should be people who can contribute positively to that process and have a shared understanding of what is expected of them during the session (Sammon, McAvoy \& Owens, and 2009:537). The facilitator should also tell the participants what will be covered during the session (Silvester, 2007, p. 3).

The last item that needs to be addressed under the preparation phase is the organisation (Parker, 2010). "An organisation is a coordinated unit" formed by a single-minded group of people in order to achieve a specific goal (Gibson, Invancevich, Donnelly \& Konopaske, 2009:14). The participants come together because they want their organisation to achieve a certain human need. That human need is the gap which they saw in the market. Human needs become customer needs or requirements which become the focus of an organisation in its quest to meet or exceed customer satisfaction (Campbell, 2011:4). Hence, organisation preparation must identify the resources, capabilities and competencies that would be needed by the organisation (Coulter, 2008:109). Complete efficiency and effectiveness is what organisation preparation focuses on (Pakhare, 2012:1). Organisational effectiveness is dependent on whether the organisation utilises the resources it has invested on itself efficiently. Overall organisational effectiveness also includes a focus on individual, team and group effectiveness. Individual effectiveness is influenced by the ability, skill, knowledge, attitude, motivation and stress whereas group effectiveness is influenced by cohesiveness, leadership structure, status, roles and norms. Organisational effectiveness is influenced by the environment, technology, strategic choices, structure, processes and culture. Organisational effectiveness leads to an organisation's effective performance (Gibson, et al., 2009:15).

\section{An overview of the strategic planning process}

The strategic planning process is the second phase of the strategic process. An overview of the strategic planning process involves "looking at the past, the present and the future". The process "entails an assessment of the organisation, its resources, and its environment and encompasses the setting of objectives" (Carrol, 2010:1). An overview of the strategic planning process also focuses on the roles of the sponsor, the facilitator and the participants as well as on the rules of engagement (Parker, 2010, Workshop). The sponsor is the person who is responsible for the success of the organisation and provides funding for the project. He helps in the overcoming of organisational and political obstacles (Campbell, 2011:61). Sponsors invite appropriate participants who have a shared understanding and could be partners in the strategic planning process (Kaufman, Oakley-Brown, Watkins \& Leigh, and 2003:85).

\section{Strategic intent}

"Strategic intent is about creating a sense of urgency through the setting of an overarching ambitious goal that stretches the organisation and focuses on winning in the long run, which gives a sense of direction and purpose to members of the organisation" (Ehlers \& Lazenby, 2007:65). The strategic intent can be the basis of the business purpose or mission, vision, brand promise and organisational values (Parker, 2010, Workshop). Organisations that decide on a strategic intent pursue their strategic objectives relentlessly and at times even obsessively. They become offensive against their competitors to an extent that they throw them off-balance. Their rivals are left behind in a game of catch-up. Cases in point are Toyota that overtook General Motors and Nike that overtook Adidas (Thompson, Strickland \& Gamble, 2007). The elements of the strategic intent are briefly discussed below.

- The mission statement or core purpose is the organisation's reason for existence beyond creating shareholders' wealth (Collins \& Porras, 2005:76). It tells the world "who we are, what we do and why we are here" (Thompson, 
Strickland \& Gamble, 2007:24). Whereas the strategic plan is fixed to time horizon or timeline, the core purpose is a constant beacon that continuously stimulates change through innovation. The constant expansion of the ideal being pursued is never attainable. As a result, organisations with good mission statements are relentlessly future driven. They are uncomfortable with the status quo (Parker, 2007). The mission statement must focus on the needs of the customers (Kaplan \& Norton, 2008). It must reflect the noble values and beliefs of what the founders of the organisation envisioned when they put life into it. As a result the employees become inspired, focused and have direction (Gallo, 2010).

- Vision is the bold and noble direction which the organisation is about to pursue (Thompson, et al., 2007). The vision must be so inspiring that it stirs people's blood to an extent that they would not like to fall asleep when thinking about it. The vision must be so inspirational that it becomes intoxicating to its evangelists (Gallo, 2011).

- Brand promise is when the organisation delivers the product or services to its customers "in a consistent manner to attain and maintain the desired identity, a coherent corporate image and a corporate reputation" (Punjaisri \& Wilson, 2007:59). The brand promise needs to be honoured by the organisation to the customers at each and every service station (Punjaisri \& Wilson, 2007:59). The brand promise must be distinctive for the products for which it is registered (Muhlberg, 2005:31).

- Organisational culture refers to the rules of organisational life or the corporate religion and it unites the organisation around the mission and vision statements (Urde, 2003:1018). Unless the organisation has organisational culture which is distinctive and unique to it, it may not continue to exist. It is meant to overcome unforeseen problems (Ohemeng, 2011:470). It is a timeless internal element which exists independent of the organisation and enables it to survive during turbulent times and achieve success. Organisational culture is cultlike and creates a tight-knit group of workforce with ntense loyalty to the organisation which makes them happy, productive and religiously disciplined (Collins \& Porras, 2005:74).

\section{Taking 360 degrees stock}

Going into a war zone is a matter of life and death. It therefore becomes imperative for the generals to thoroughly assess the weather conditions as well as the terrains where the fight will take place. In addition, the generals must assess their armies' strengths and weaknesses, because if they do not have superiority, there is no guarantee that they would win (Michaelson \& Michaelson, 2011:26). World class organisations do not just rush into a new industry like fools. They carefully assess their industry's environment and the strengths and weaknesses of their organisations. The 360 degree assessment involves the assessment of the external environment as well as the internal environment of the organisation. Once this is done, it gives way for the formulation of the organisation's strategy.

\section{Formulation of strategy}

The fifth phase of the strategic planning process is the formulation of the organisation's strategy (Parker, 2010). Strategies of quality organisations are formulated by using two important strategy tools. These tools are the strategy map and the balanced scorecard (Anagnospoulos, 2010:12). A strategy map is a one-page visual or graphical representation of the four perspectives and showing the cause-and-effect linkages in each perspective (Niven, 2006:27). On the other hand the Balanced Scorecard is also known as 'balanced' because it combines both financial and nonfinancial indicators in one sheet. It also combines long-term strategy as well as the short-term strategy in the same sheet. It usually has four perspectives with the financial perspective indicating to management of what has happened in the organisation (lagging indicators), whilst the other three perspectives indicate to management whether the business will succeed in the future (lead indicators) (Pandey, 2005:55).

Not only does the balanced scorecard create a balance between the financial and non-financial perspectives, it creates linkages between them as well (Sinha, 2006:74). Components of strategy formulation are the strategy themes, strategies, smart objectives and the quality requirements. Strategy themes are the vertical slices that are found within the strategic map and are made up of related objectives (Kaplan \& Norton, 2008b:68; Kaplan \& Norton, 2008c:104). Strategies are objectives, which describe "what we must do well in each of the four perspectives in order to implement our game plan" (Niven, 2006:18). Smart objectives are the building blocks of the strategy which specify the purpose that needs to be achieved for the organisation's overall mission (Rohn, 2008, p. 3). Quality requirements are the determination of the stakeholders' requirements and expectations (Schneiderman, 2006:2). The requirements include the 
person who will be responsible for each step, the time-frame required for each step as well as the definite dates for beginning and ending each step (Yavitz \& Newman, 1982:115).

\section{Refinement and consolidation of the strategic plan}

The formulation of the strategy is followed by the refinement and consolidation of the strategic plan. This process involves the taking of the organisation's newly formulated strategy to the 'corridors and cubicles' of the organisation (Niven, 2006:199). When the strategy is taken through the various units of the organisation through the process of cascading, there is organisational integration that makes the organisation's various units to be interdependent of each other. This in turn facilitates information and process integration (Berente, Vandenbosch \& Aubert, 2009:121). Cascading is the process of developing the balanced scorecard at each and every level of the organisation, by identifying the strategic objectives and measures that the lower level groups would use to track their progress in achieving organisational goals (Niven, 2006:200). Together with the strategy map, they convert strategic plans into performance plans, starting with strategic objectives down the hierarchy to the operational and individual levels (Kaplan \& Norton, 2008:158).

\section{Implementation of the strategic plan: - Performance Management System}

When the strategic plan and the business plan have been cascaded down to the operational level for delivery by the organisation's workforce and where their execution is critical, they are seamlessly flown and aligned into the Performance Management System. Therefore Performance Management System should begin with a clear understanding of the organisation's strategic planning process (Parker, 2010). Performance Management System is defined as the organisation's critical success factor for a flawless implementation of strategy. This implementation is achieved by linking the organisation's strategic goals and objectives (clustered into strategic themes) with its budget and operational systems in order to achieve organisational efficiency, effectiveness and accountability (Verweire \& Van den Berghe, 2004:3). Figure 2 below shows a Link between Organisation Strategy and Operations.

\section{Figure 2: Linking Organisation Strategy and Operations}

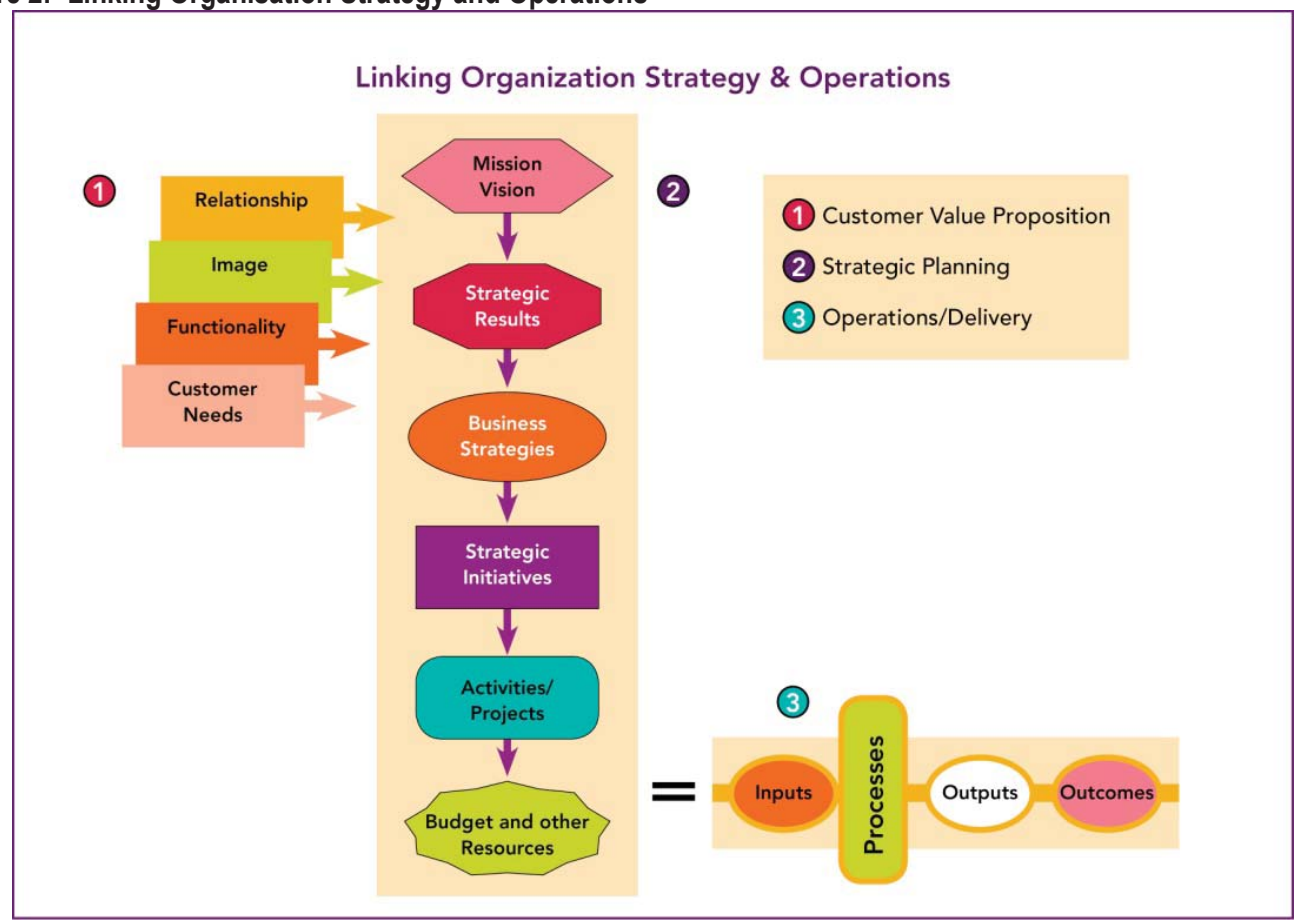

Source: Rohm \& Halbach (2011:1). 
Performance Management System will deliver a sustained performance provided it is integrated. Performance Management is integrated when the organisation's strategy is linked to direction and goal-setting objectives, operational processes, support processes, evaluation and control as well as the organisational behaviour. There is integration when the organisation is strategically aligned and focused. The organisation is focused and aligned when everyone within the organisation is focusing towards the same direction with a common purpose and when its resources and systems are integrated to achieve that purpose (Verweire \& Van den Berghe, 2004).

\section{Strategy implementation components}

Once a sound strategic plan is in place and it has been cascaded from the corporate level to the operational and individual level, the strategic plan implementation begins. Strategy implementation should not be regarded as distinct from strategy formulation. Strategy formulation and strategy implementation are interdependent and are only two sides of the same coin (Hrebiniak, 2006:13). However, there are certain components that must be put in place as critical success factors for strategy implementation to succeed. These components are policies and procedures, installation of information and operating systems, installation of organisational culture, transformational leadership, human capital that embrace competencies and capabilities, budget and accountability and the tying of rewards and incentives. Without these drivers, strategy implementation will encounter several obstacles and flawed (Ehlers \& Lazenby, 2007: 216).

The above components for successful strategy implementation are the foundational framework for organisational capacity. The company has organisational capacity when it consistently and efficiently has the ability to "mobilise and sustain the process of change required for the execution of strategy" (Kaplan \& Norton, 2004, p. 275). An organisation has organisational capacity when it possesses organisational agility, in addition to when it can coordinates and integrates seamlessly its internal activities (Cloud Citizen, 2013:1). It includes the ability of the organisation to "apply its skills, assets and resources to achieve its goals" (Aidstar-Two, 2009:52). These components enable the organisation to enhance efficiency, effectiveness and create a sustainable growth (Watson, 2003:1). A brief discussion of each of these components is as follows.

\section{Policies and procedures}

Policies and procedures are tools that facilitate the implementation of strategy. They are guidelines and administrative practices that direct the decisions and actions of managers and employees in the implementation of the organisational strategy. Policies and procedures standardise routine decisions and they promote coordination and consistency across organisational units (Ehlers \& Lazenby, 2007:263). Once operational policies are developed, they should be infused into the implementation system to facilitate strategic plan implementation. Within the implementation systems, the operational policies are absorbed by the various implementation structures to ensure efficiency and effectiveness (Hüpkes \& Zibung, 2008:248; Vairo, Häring, Dabbert \& Zanoli, 2009: 217).

\section{Information and operating systems}

Organisational strategies cannot be executed without the installation of the internal information and operating systems. They can strengthen the organisational capabilities and provide linkages within and between value chains. They are able to track the quality of product at each and every production step in order to meet the required standards. With information and operating systems, organisations are able to monitor and track minute by minute, operational performance and are able to identify problems timeously, in order to put the corrective measures (Thompson, et al., 2007:401-403). Information and operating systems facilitate the information flows and the business process integration (Berente, Vandenbosch \& Aubert, 2009:119). They have become the lifeblood of organisations without which they would not be able to survive (Gates, 1999:1).

\section{Instillation of organisational culture}

A strong organisational culture need to be instilled within the organisation to support the implementation of the strategy. An organisational culture reflects the organisation's identity and it conveys to every employee how things are done within the organisation. It is made up of organisational values, norms and beliefs that guide the actions of organisational members (Ehlers \& Lazenby, 2007:223). Unless the organisation has organisational culture which is distinctive and 
unique, its continued existence is limited. Culture is meant to overcome unforeseen problems (Ohemeng, 2011:470). It is responsible for organisational commitment, job performance, employee engagement and effectiveness (Jiang, Lin \& Lin, 2010:239). Organisational values and beliefs create an unparalleled commitment amongst the employees who work hard for the success of their organisation (Aadland, 2010:463). World-class and visionary organisations only hire employees who are culturally fit (Gallo, 2011:189).

\section{Transformational distributed leadership}

Strategy implementation requires a strong transformational and distributed leadership, which is spread at each and every level of the organisation. Transformational and distributed leadership has the capacity to transform itself continuously and to adapt to the changing circumstances. This leadership is able to determine the direction of the organisation and align the employees behind the organisational vision. Organisations that lack this leadership cannot survive (Parker, 2007:4748). Organisational leadership should instil focus and clarity at all levels of the organisation (Syrett, 2007:83).

\section{Human Capital}

Human resources are indispensable for any strategy implementation. The knowledge, experience and skills which they possess are known as human capital (Ehlers \& Lazenby, 2007:86). Management must strive to get the right people and the best people who fit the organisational culture (Collins, 2001, p. 184; Olsen, 2007, p. 125). Human resources must possess organisational capabilities which are the organisation's capacity to deploy organisational resources or to perform its tasks by converting them into outputs (Boguslauskas \& Kvedaraviene, 2009:77).

In addition to capabilities they must have competencies for the jobs they are employed to do. Competencies focus on the skills and knowledge that the employee must possess in relation to the products or services which the organisation offers to targeted customers. The competency profile of the employee is made up of knowledge, skills and values which are characteristics for producing outstanding performance in a given job (Kaplan \& Norton, 2004:233). An employee who values results-oriented approach is as well a team player and customer partner. Strategy implementation can be delayed until there is a substantial human capital readiness to serve the targeted customers (Kaplan \& Norton, 2008:105).

\section{Budget and accountability}

The Balanced Scorecard communication tool is incomplete without the performance targets and the strategic initiatives (Niven, 2006:180). Sixty percent (60\%) of organisational strategies fail because most organisations failed to link budgets to the strategies (Niven, 2006:11). Resource allocation plan or budgeting is meant for the organisation's strategic initiatives (Ehlers \& Lazenby, 2007:257). Initiatives are 'the action steps, processes, projects and plans' that describe how performance targets will be met (Niven, 2006:179). The executive team establishes a budget or a pool of fund for the support of the strategic initiatives (Kaplan \& Norton, 2008:115). The executive team establishes accountability for the strategic initiatives by appointing theme owners for each strategic initiative. The theme owner establishes the theme team that is assigned with the power to implement the strategic initiative. A committee member is appointed to give a monthly report on the progress or direction of the strategic initiative in achieving the targeted results. Should the strategic initiative be neglected or abandoned, the associated objective, measure and target could be missed. Therefore, accountability guarantees strategy implementation (Kaplan \& Norton, 2008:119).

\section{Tying rewards and incentives}

Tying rewards and incentives to organisational strategy help with the implementation of organisational strategy. Rewards and incentives improve employee commitment as well as behaviour consistency. They also reward employees for accomplishing and performing assigned tasks. As a result, they become the motivator for strategy implementation. Rewards and incentives are in various formats, such as status, recognition, awards, job security, promotion, perks and many others (Ehlers \& Lazenby, 2007:229).

\section{Evaluation of the strategic plan}


The evaluation of the strategic plan is the final phase of the strategic planning process. The monitoring and evaluation phase focuses on how good, useful or successful the strategic plan is, and what else needs to be done and why. The focus is on the internal workings of the organisation and what is working well is left unchanged whereas what is not working well is tackled and corrected in order to achieve the desired results. The objective of the evaluation is to ensure that the strategic plan succeeds (Patterson \& Radtke, 2009:3). The monitoring and evaluation move the strategic plan from a theory phase to the implementation phase by monitoring if the goals are being achieved; whether resources are adequate and whether the employees understand and implement as required (Gordon, 2011:1). The evaluation and monitoring of the strategic plan uses key performance indicators, the set of measures that enable management to know how the organisation is performing (Grensing-Pophal, 2011:242).

\section{Research Methodology}

The research design is a descriptive quantitative research. This type of research does not manipulate the independent variable in order to see or determine if the dependent variable is affected (Yegidis \& Weinbach, 2002:109). It enables the researcher to observe, describe, analyse and then interprets what has been observed (Babbie, 2002:81). The descriptive research helped to "provide accurate measurement of the distribution of variables and to identify associations and correlations between them (Babbie, 2002). The researcher is then able to predict the dependent variable when he knows the measurement of the independent variable (Yegidis \& Weinbach, 2002:153 \& 154). Questionnaires were used to obtain information from respondents. Each questionnaire contains statements and the respondents reflect their opinions or attitude on each of the statements given. The respondent's level of agreement with each of the statement is measured on a five-point Likert scale. "Agree" and "strongly agrees" are indicative of the greater importance attached to the practice as compared to the other practices of "strongly disagree"; "disagree" and "neutral". The mean score of more than 3.00 for an item is an additional indication that the respondents agree with the statements. In order to measure reliability, the Cronbach's Alpha Coefficient instrument is normally used to measure the internal consistency or the average correlation of items in the survey instrument. However, validity measurement was not used because of the small number of completed questionnaires. The survey questionnaires used to gather data was found to be highly reliable.

\section{Research population and samples}

The population was defined as companies registered in South Africa and listed at the Johannesburg Stock Exchange. Such organisations should have been registered for not less than five years. One hundred questionnaires were e-mailed to the sampled organisations which were randomly selected. Based on the 2011 Johannesburg Stock Exchange handbook, the 100 randomly selected organisations constituted a quarter of all the listed organisations. All selected organisations confirmed telephonically to have received the e-mailed questionnaires. A total of 46 completed questionnaires were received, each from one organisation. The completed questionnaires represent a response of $46 \%$ of the randomly selected organisations. These were further analysed.

The respondents were mostly directors or general managers (50\%). The other respondents were senior managers (10.9\%); assistant managers (8.7\%); middle managers (8.7\%) whilst others represented $15.2 \%$. A negligible number of respondents were curators, portfolio managers, recruitment managers or secretaries. The organisations included a sample range from small organisations to large organisation. Small organisations, which made up $26.1 \%$ of the sample, have between 11-50 employees; medium organisations which made $21.7 \%$ of the sample have $51-250$ employees and large organisations which made up $52.2 \%$ of the sample, have above 250 employees.

\section{Research finding}

In terms of the practice of preparation for strategy development, a majority of the respondents (65.2\%) agreed/strongly agreed that their organisations should embrace such practices, with a mean score of between 3.72 and 4.20 . In terms of the overview of the strategic planning process practice, a majority $(80.5 \%)$ of the respondents agreed/strongly agreed that it should be practiced, with a mean score of between 3.13 and 4.07. In terms of deciding on the strategic intent practice, an overwhelming $75.9 \%$ of respondents agreed/strongly agreed that it should be adopted, with a mean score of between 3.89 and 4.46 . Taking 360 degree stock practice got $77.9 \%$ of respondents who agreed/strongly agreed with a mean score of between 3.91 and 4.26 . The formulation of strategy got a majority of $84.3 \%$ of respondents who 
agreed/strongly agreed with a mean score of between 3.91 and 4.42. The practice of refining and consolidating the strategic plan got the majority of $58.6 \%$ of respondents who agreed/strongly agreed with a mean score of between 3.54 and 4.04. Implementation of the strategic plan practice got a majority of $65.1 \%$ of respondents who agreed/strongly agreed, with a mean score of between 3.63 and 4.09. Finally, the evaluation of strategic plan got a majority of $64.3 \%$ of respondents who agreed/strongly agreed that it should be practiced, with a mean score of between 3.67 and 4.09 .

\section{Strengths and Limitations of the study}

The strengths of this study are its comprehensive literature review. It was on the basis of the comprehensive literature review that the survey questionnaire was developed. The survey questionnaire enabled the researcher to reach the targeted population. However, by its nature, a descriptive study needs a large sample for it to be definitive. The representation of the organisations under this study was insignificant, with a total of 46 organisations, as opposed to the researchers' initial intention to survey 100 organisations. As a result, validity testing could not be done. It is recommended that future research should target about 200 organisations that are listed on the Johannesburg Stock Exchange. In addition each organisation should be able to have at least 5-10 people who are able to complete the survey questionnaire.

\section{Conclusion and implication}

In conclusion literatures reveal that only less than $10 \%$ of organisational strategies succeed. This discouraging situation was the brain child of this research, which was intended to add value to the body of knowledge by identifying those critical success factors that could make organisational strategies a successful one. The study has closed a gap in knowledge by focusing on quality practices of strategic planning that could impact on strategy implementation and overall organisational success.

In a nutshell organisations that embrace the outcome of this study's findings may become highly successful in the implementation of their organisational strategy. The unpredictability of external forces can no longer be regarded as threat. The new rule will certainly liberate many organisations from their ineffective business practices.

\section{References}

Anagnostopoulos, K.P. \& Elmasides, G. (2010). Strategic plan in a Greek manufacturing company: A balanced scorecard and strategy map implementation. International Journal of Business and Management, 5(2):12-25.

Babbie, E.R. (2002). The basics of social research. (2nd edition.) Belmont, California: Thomson/Wadsworth.

Berente, N., Vandenbosch, B. \& Aubert, B. (2009). Information flows and business process integration. Business Process Management Journal, 15(1):119-141.

Bless, C. \& Higson-Smith, C. (2004). Fundamentals of social research methods. (3rd Edition.) Lansdowne, Cape Town: Juta Education.

Campbell, G.M. (2011). The Complete Idiot's Guide to Project Management. (5 $5^{\text {th }}$ edition.) ALPHA - A Member of Penguin Group (USA) Inc.

Carroll, A.B. (2010). Three types of management planning: Making organisations work. Management Quarterly, vol. 34, pp. 1-2. Available from: http://www.questia.com/googleScholar.qst?docld=5002194623 (Accessed: 10/06/2007).

Čater, T. \& Pučko, D. (2010). Factors of effective strategy implementation: Empirical evidence from Slovenian business practice. Journal for East European Management Studies, 15(3):207-236.

Cloud Citizen (2011). What is organisational capital? Available from: http://www.cloudcitizen.com/blog2011/10/what-is-organisationalcapital.html, (Accessed on 03/04/2013)

Cokins, G. (2004). Performance management: Finding the missing pieces (to close the Intelligence Gap.) Hoboken, New Jersey: John Wiley \& Sons, Inc.

Collins, J.C. \& Porras, J.I. (2005). Built to last: Successful habits of visionary companies. New York: Harper Business.

Coulter, M. (2008). Strategic management in action. (4th edition.) Pearson Education, Inc., Saddle River, New Jersey: Pearson Prentice Hall.

Crittenden, V.L. \& Crittenden, W.F. (2008). Building a capable organisation: The eight levers of strategy implementation. Business Horizons, 51(4):301-309.

Cru Press Green (2010). The strategic planning process. Available from: http://crupressgreen.com (Accessed: 06/10/2011).

Ehlers, T. \& Lazenby, K. (2007). Strategic management: Southern African concepts and cases. (2nd edition). Pretoria: Van Schaik.

Ferguson, N. (2008). "The end of prosperity?" Time Magazine, October, 02, 2008, 172(15):18-21. 
Frigon, N.L. \& Jackson, H.K. (2009). Enterprise excellence: A practical guide to word-class competition. Hoboken, New Jersey: John Wiley \& Sons, Inc.

Gates, B. (1999). Business @ the speed of thought: Using a digital nervous system. New York: Warner Brooks, Inc.

Gibson, J.L., Ivancevich, J.M., Donnelly, Jr. J.H. \& Konopaske, R. (2009). Organisations: Behaviour, structure, processes. (13 edition). Irwin, New York: McGraw-Hill.

Gordon, A. (2011). Monitoring and evaluating strategic plans. Available from: http://EzineArticles.com/?expert=Alexander Gordon. (Accessed: 28/07/2011).

Grensing-Pophal, L. (2011). The Complete Idiot's Guide to Strategic Planning. ALPHA - A Member of Penguin Group (USA) Inc.

Heppner, P.P. \& Heppner, M.J. (2004). Writing and publishing your thesis, dissertation and research: A guide for students in the helping professions. Belmont, CA: Brooks/Cole.

Hrebiniak, L.G. (2006). Obstacles to effective strategy implementation. Organisational Dynamics, 35(1):12-31.

Hrebiniak, L.G. (2008). Making strategy work: Overcoming the obstacles to effective execution. Ivey Business Journal, March/April, pp. 1-6.

Jiang, D.; Lin, Y. \& Lin, L. (2010). Business moral values of supervisors and subordinates and their effect on employee effectiveness. Journal of Business Ethics, no. 100, pp. 239-252.

Kaplan, R.S. \& Norton, D.P. (2008a). The execution premium. Boston, Massachusetts: Harvard Business School Publishing Corporation.

Kaplan, R.S. \& Norton, D.P. (2008b). Mastering the management system. Harvard Business Review, January, pp. 63-77.

Kaplan, R.S. \& Norton, D.P. (2008c). How to implement a new strategy without disrupting your organisation. Harvard Business Review, March, pp. 100-109.

Kaufman, R.; Oakley-Browne, H.; Watkins, R. \& Leigh, D. (2003). Strategic planning for success: Aligning people, performance, and payoffs. San Francisco, CA: Jossey-Bass/Pfeiffer. A Wiley Imprint.

Khadem, R. (2008). Alignment and follow-up: Steps to strategy execution. Journal of Business Strategy, 29(6):29-35.

Khan, A. (2007). Developing world class organisations. American Chronicle. Available from: http://www.americanchronicle.com, (Accessed: 06/08/2012)

Köseoğlu, M.A., Barca, M., Karayormuk, K. \& Edas, M. (2009). A study on the causes of strategies failing to success. Journal of Global Strategic Management (JGSM), 3(2):77-90.

McGraw, B. (2009). The new face of strategic planning: Bridging it with project management is the key to success. PM World Today, $\mathrm{XI}(\mathrm{IV}): 1-4$

Michaelson, G.A. \& Michaelson, S. (2011). The complete Sun Tzu for business success: Use the classic rules of the art of war to win the battle for customers and conquer the competition. Avon, Massachusetts: Adams Media Corporation.

Muhlberg, H. (2005). The law of the brand: A practical guide to branding law in South Africa. Cape Town: Zebra Press. A division of New Holland Publishing (South Africa) (Pty) Ltd.

Niven, P.R. (2006). Balanced scorecard step-by-step. Hoboken, New Jersey: John Wiley \& Sons, Inc.

Nyembezi, V. (2009). Development of a performance management system for the SABC (Port Elizabeth). A published Masters degree in Business Administration thesis. Port Elizabeth: Nelson Mandela Metropolitan University Business School.

Ohemeng, F.L.K. (2011). Institutionalizing the performance management system in public organisations in Ghana: Chasing a Mirage? Public Performance and Management Review, 34(4):467-488.

Olsen, E. (2007). Strategic planning for dummies. Indianapolis, Indiana: Wiley Publishing Inc.

Pakhare, J. (2012). Organisational Development. Available from: http://www.buzzle.com/articles/organisational-development.html (Accessed: 02/23/2012).

Pandey, I.M. (2005). Balanced scorecard: Myth and reality. Vikalpa, 30(1):51-66.

Parker, A.J. (2007). Validity of world-class business criteria across developed and developing countries. Unpublished Doctoral thesis. Johannesburg: University of Johannesburg.

Parker, A.J. (2010). Workshop. pp. 1-7.

Patterson, S.J. \& Radtke, J.M. (2009). Strategic communications for non-profit organisation: Seven steps to creating a successful plan. (2nd edition.) John Wiley \& Sons.

Pritchard, K. (2008). Employee engagement in the UK: Meeting the challenge in the public sector. Development and Learning in Organisations, 22(6):15-17.

Pulakos, E.D. (2009). Performance management: A new approach for driving business results. Chichester: John Wiley \& Sons.

Resnick, H.S. (2010). Organisational strategic planning processes. Available from: http://www.worksystems.com/services/strategicplanning.html (Accessed: 04/05/2010).

Rohm, H. (2008). Is there any strategy in your strategic plan? Balanced Scorecard Institute. Available from: http://www.balancedscorecard.org (Accessed: 08/11/2012).

Rohm, H. \& Halbach, L. (2011). A balancing act: Sustaining new directions. Perform Magazine, 3(2):1-8. Available from: http://www.balancedscorecard.org/Portals/o/PDF/perform2.pdf (Accessed: 06/10/2012).

Royse, D. (2008). Research methods in social work. (5 $5^{\text {th }}$ edition.) Belmont, USA: Thompson Brooks/Cole.

Russell, R.S. \& Taylor, B.W. (2009). Operations Management: Creating value along the supply chain. (6th edition.) Hoboken, N.J.: John Wiley \& Sons. 
Sammon, D., McAvoy, J. \& Owens, I. (2009). Agile teams: Reflective debate and shared understanding. Proceedings of ECIME 2009. The $3^{\text {rd }}$ European Conference on Information Management and Evaluation held at the University of Gothenburg, Sweden on 1718 September 2009, pp. 535-543.

Schilder, D. (1997). Strategic planning process: Steps in developing strategic plans reaching results Harvard family research project: Harvard Graduate School of Education. Available from: http://www.hfrp.org/publications-resources/browse-ourpublications/strategic-plans (Accessed: 02/08/2012.)

Schneiderman, A.M. (1999-2006). How to build a balanced scorecard. Available from: http://www.schneiderman.com/Concepts/Scorecard/How to build a Balanced Scorecard/how to build a BSC intro.htm (Accessed: 2010/09/30.)

Shapiro, J. (2010). Strategic planning toolkit. Available from: toolkits@civicus.org (Accessed: 06/12/2012).

Silvester, K. (2007). Report on training of trainers' (TOT) workshop on HIV and Aids. Held at Women's Forum for Research and Training (WFRT), 5 - 9 December 2007. Available from: http://www.wfrt.org/downloads/en/hiv/reports/5.TOT-Report-dec07.pdf. (Accessed: 29/06/2011).

Sinha, A. (2006). Balanced scorecard: A strategic management tool. Vidyasagar University Journal of Commerce, vol. 11:71-81.

Speculand, R. (2009). Six necessary mind shifts for implementing strategy. Business Strategy Series, 10(3):167-172.

Thompson, A.A. Jr., Strickland, A.J. III \& Gamble, J.E. (2007). Crafting and executing strategy: The quest for competitive advantage: Concepts and cases. (16 ${ }^{\text {th }}$ edition.) New York: The McGraw-Hill Companies, Inc.

Urde, M. (2003). Core value-based corporate brand building. European Journal of Marketing, 37(7/8):1017-1040.

Verweire, K. \& Van den Berghe, L. (2004). Integrated performance management: A guide to strategy implementation. London, Thousand Oaks, California: Sage Publishers.

Von Eck, C. (2007). Change dynamics and related leadership competencies. Leading people through change and uncertainty. Unpublished Doctoral thesis in Philosophy. Johannesburg: University of Johannesburg.
Watson,
T.J.
(2003).
Building
organisational
capability.
Available from:

http://community.flexiblelearning,net.au/ManagingFlexibleDelivery/content/article 4, (Accessed 20/05/2011).

Wildermuth, C.M.S. \& Pauken, P.D. (2008). A perfect match: Decoding employee engagement: Part 1: Engaging cultures and leaders. Industrial and Commercial Training, 40(3):122-128.

Yavitz, B. \& Newman, W.H. (1982). Strategy in action: The execution, politics and payoff of business planning. New York: The Free Press.

Yegidis, B.L. \& Weinbach, R.W. (2002). Research methods for social workers. (4th edition.) Boston: Allyn \& Bacon. 